\title{
Assessing Executive Functions of Turkish-German Bilinguals, Turk- ish Speaking Children with S/LI and Turkish Speaking Monolingual Children
}

\author{
Ayşe Aydın Uysal ${ }^{1 *}$ and ilknur Maviş ${ }^{2}$ \\ ${ }^{1}$ Assistant Professor, Department of Special Education, Kocaeli University, Kocaeli, Turkey \\ ${ }^{2}$ Professor Doctor, Faculty of Health Sciences, Department of Speech and Language Therapy, Anadolu \\ University, Eskişehir, Turkey
}

*Corresponding author: Ayşe Aydın Uysal, Assistant Professor, Department of Special Education, Kocaeli University, Kocaeli, Turkey, E-mail: aysea@anadolu.edu.tr

\begin{abstract}
Specific language impairment has been found to be associated with dysfunction in executive functions whereas bilingual children are thought to be superior at these skills compared to monolingual children. The present study investigated executive functions in three groups of children: Turkish-German bilinguals, Turkish speaking children with $\mathrm{S} / \mathrm{LI}$ and Turkish speaking monolingual children. Groups were matched on first language and chronological age. EF performance tapping conflict inhibition/attentional control, inhibition, short term memory, working memory, monitoring and updating were compared among groups. Children with $\mathrm{S} / \mathrm{LI}$ scored at a lower level compared to other two groups on all executive functions tasks used in this study. Bilingual children outperformed the other groups on most of the tasks measuring working memory and inhibition.
\end{abstract}

\section{Keywords}

Specific language impairment, Bilingualism, Executive functions, Conflict inhibition, Short term memory, Working memory, Verbal fluency

\section{Introduction}

Specific Language Impairment (S/LI) is a disorder in which language ability is delayed despite having no obvious hearing, cognitive or neurological problems which impede the lexical, morphosyntactic and discourse-pragmatic abilities [1]. Although children with S/ LI have non-advantage IQs in the average range, in recent years, there's increasing evidence that they have some executive function difficulties $[2,3]$.
Executive functioning (EF) is used as an umbrella term for mental operations that require the coordination of several sub-processes to achieve a particular goal. These include attention, memory, inhibition, planning, shifting, flexible thinking and verbal fluency [4].

Of these functions, "inhibition" is the most reliably documented dysfunction in children with $S / L I[5,6]$. Inhibitory control, the ability to suppress the activation, processing or expression of information that interferes with the efficient attainment of a cognitive or behavioral goal, is thought to be the basis of the other EFs and has a strong relationship with language [7-9]. In tasks measuring inhibition, people are asked to suppress a dominant response in order to perform a conflicting action. These tasks can include verbal as well as nonverbal responses.

Verbal fluency, the ability to generate novel verbal responses [10] is another executive function domain which subsequently been established in many independent studies to be a hallmark of S/LI in children [11-14]. Typical examples of verbal fluency are semantic and phonemic fluency tasks. In phonemic fluency tasks, as many words as possible starting with a certain phoneme (eg. $/ \mathrm{s} /$ ) are asked to generate in one minute while words belonging to a certain semantic category (eg. vehicles) are asked in semantic fluency tasks [15]. The fluency tasks are used as an efficient screening instrument of general verbal functioning since it requires one to access mental lexicon, focusing on task, selecting

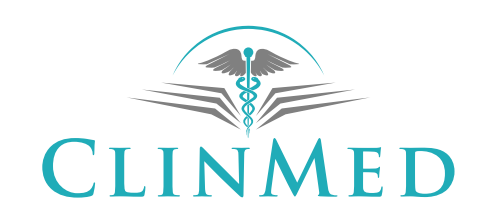

INTERNATIONAL LIBRARY
Citation: Uysal AA, Maviş I (2018) Assessing Executive Functions of Turkish-German Bilinguals, Turkish Speaking Children with S/LI and Turkish Speaking Monolingual Children. Int Arch Commun Disord 1:008. Received: January 09, 2018; Accepted: April 24, 2018; Published: April 26, 2018

Copyright: (c) 2018 Uysal AA, et al. This is an open-access article distributed under the terms of the Creative Commons Attribution License, which permits unrestricted use, distribution, and reproduction in any medium, provided the original author and source are credited. 
words meeting certain constraints and avoiding repetition [16]. These processes are strongly linked to goal-directed behaviors like flexibility of thoughts, strategic planning and error-monitoring [17].

Consistent findings have emerged in children with S/ LI regarding "short term memory" and "working memory" [18-22]. Short term memory is responsible for holding sensory events, movements, and cognitive information like digits, words or other items for a short period of time. In contrast to short term memory, working memory refers to cognitive processes used for both temporarily maintaining and also manipulating information. It is thought to be strongly related with some higher order cognitive abilities like reasoning, problem solving or learning [23]. Typical tasks measuring short term memory and working memory are digitspan tasks. Digitspan Forward is a task of short-term auditory memory, sequencing, and simple verbal expressions [24] while Digitspan Backwards is more sensitive to deficits in working memory. Children with S/LI are reported to perform poorly on both measures of Digitspan Forward and Digitspan Backwards [25-28]. However, discussions continue about whether working memory deficits in S/ $\mathrm{LI}$ are specific to processing, manipulation, and storage of information from the verbal domain [29] or the result of a "generalized slowing" across linguistic and nonlinguistic tasks alike $[21,30]$.

Bilingual children with TD or S/LI? also show similar difficulties in the early stages of acquisition of language to monolingual children with S/LI [31-34]. After achieving proficiency in two languages, bilinguals show cognitive gains compared with monolinguals and children with S/LI on tasks requiring executive functions [35-38]. Numerous reasons are proposed for bilingual children's superiority on tasks requiring executive functions. Of these, dual-language management has received the most attention [37,38]. Research conducted by Carlson and Meltzoff (2008) revealed an increased ability on tasks of working memory and attention shifting among bilingual children compared to monolinguals and early second language learners. Another research by Poarch and van Hell (2012) [39] has also indicated increased attention and inhibition abilities among bilinguals. The authors explain their findings by asserting that bilingual children constantly need to choose one lexeme and inhibit the other activated one. However, Costa and colleagues (2009) [37] claim that bilingualism enhances executive functions not only through choosing appropriate lexemes but also with monitoring of which language to use in different social and communicative practices.

Thus, the aim of this study was to examine whether Turkish monolingual children with $\mathrm{S} / \mathrm{LI}$ and Turkish-German bilinguals? with TD display a unique profile of neuropsychological and executive functioning compared to their age and gender matched peers with typical development on a variety of executive tasks tapping both verbal and nonverbal domains. The specific research questions to be addressed by the study were:

1. Do monolingual Turkish speaking children with $S / L I$ between 5-6 years of age exhibit impairments on executive tasks assessing conflict inhibition, short term memory, working memory and verbal fluency?

2. Do Turkish-German bilingual children between 5-6 years of age display cognitive advantages compared to their age and gender matched Turkish speaking monolingual peers with typical development on executive tasks assessing conflict inhibition, short term memory, working memory and verbal fluency?

\section{Method}

\section{Participants}

Three groups of subjects participated in the present study; Turkish speaking monolingual children with $S / L I(n=14)$, Turkish-German bilinguals $(n=14)$, and a control group of? monolingual children with typical development $(n=14)$. There were 8 males and 6 females in each group. The mean ages of the groups were as follows: children with $\mathrm{S} / \mathrm{LI}, 5$ years; 9 months (SD $=8.5$ months, $\mathrm{R}=60-83$ months), bilingual children, 5 years; 10 months (SD $=8.2$ months, $R=60-83$ months) and children with typical development, 6 years 1 month (SD $=8$ months, $\mathrm{R}=60-83$ months) (Table 1 ).

The S/LI group was recruited from Anadolu University Speech and Language Therapy Center units with the help of speech and language therapists (SLTs) and psychologists. Based on criteria used to identify S/LI [1] children with normal hearing (hearing deficit below 25 $\mathrm{dB}$ ), and normal nonverbal IQ (IQ above 85 on Leiter) were included. Language abilities of children with $\mathrm{S} / \mathrm{LI}$ were at least 12 months below their chronological age as measured by a standardized language test in Turkish (TEDIL) [40] and no participants had diagnosis of neurological impairments or behavioral problems.

The bilingual children were fluent speakers of Turkish and German recruited from monolingual German-speaking schools in Berlin, Germany. L1 of all chil-

Table 1: Demographics of participants.

\begin{tabular}{|l|l|l|l|l|l|l|}
\hline Groups & Gender & \multicolumn{3}{l|}{ Age (months) } \\
\cline { 2 - 7 } & Girls & Boys & M & SS & Min. - Max. \\
\hline Monolingual Children with Typical Development & 6 & 8 & 73.7 & 8 & 60 & 83 \\
\hline Turkish-German Bilingual Children & 6 & 8 & 69.9 & 8.5 & 60 & 83 \\
\hline Children with SLI & 6 & 8 & 70.9 & 8.2 & 60 & 83 \\
\hline Total & 18 & 24 & 69 & 7.3 & 60 & 83 \\
\hline
\end{tabular}


dren was Turkish and they were all exposed to German since they were 3-years-old. Parents of the bilingual children indicated that although Turkish was the main language spoken at the home; they have been exposed to both languages while watching TV or interacting with their siblings. Informed consents were taken from all of the parents of the participants before the study.

\section{Measures}

In the study, two tasks for conflict inhibition, two for digit memory and two for verbal fluency were administered. Stroop-like Day and Night Test (verbal) and Luria's Hand Game (nonverbal) measure conflict inhibition, Digitspan Forward and Digitspan Backward measure short term memory and working memory respectively. Verbal fluency tasks refer to the ability to recall and produce words by two semantic (animals, girls' \& boys' names) and two phonemic (/k/ /b/) measures in this study.

\section{Stroop-like day-night test}

Day and Night task is a conflict inhibition task in which children have to suppress a dominant response associated with a perceptual stimulus while selecting and executing a competing, conflicting subdominant response, coordinating a goal-directed behavior [41].

The Day and Night test begins with some practice sets. Cards with cartoon drawings presenting the sun or the moon are shown to children. Examiners ask children to say the opposite of what a picture depicts. After a maximum of three practice sets, sixteen responses are coded, and no feedback is given during testing. The number of correct responses is summed to obtain the total score.

\section{Luria's hand game}

Initially children are trained to imitate two different hand gestures by the experimenter (a fist and a pointed finger) [42]. After gaining competency on this, the child is asked to make the opposite gesture made by the experimenter. After completing six practice trials, a total of fifteen trials are completed and the number of correct gestures is the score obtained from the task.

\section{Digitspan forward}

The Digit Span Forward task required children to recall and repeat verbatim a series of numbers presented by the examiner after a two-digit practice trial with corrective feedback $[43,44]$. The first span included 2 digits, the following one included one more digit and the last span included 6 digits. The test was ended in case participants could not repeat correctly on both trials of a single string length. The subject's score was equal to the maximum of digits repeated correctly.

\section{Digitspan backwards}

The Digit Span Backward test is similar to The Digit Span Forward test $[43,44]$. However, children are required to repeat the digit spans in a reverse order. The subject has two trials for each span and the number of correct digits repeated without any error in one of two trials is summed.

\section{Phonemic/Letter fluency}

Children are required to generate words that begin with a "designated" letter as quickly as possible in 60 second time limit for each phoneme [45]. In this study, words starting with $/ \mathrm{b} /$ and $/ \mathrm{k} /$ are asked to be generated.

\section{Semantic/Category fluency}

In the semantic fluency condition, children are asked to generate as many different items as possible with the designated semantic verbal fluency category cues of "animals", "names of girls/boys" [46].

Children were tested individually at school or clinic and all tasks were presented in a fixed order in two separate sessions. Both sessions lasted approximately 30 minutes each and included a 15 minutes break halfway through.

\section{Results}

Table 2 shows the means and standard deviations of the eight executive tasks' scores elicited from the three participant groups. To investigate group differences, one-way analysis of variance (ANOVA) was performed on each test (Table 3).

\section{Conflict inhibition in monolingual, bilingual and chil- dren with specific language impairment}

Comparison of the verbal conflict inhibition performance (Day and Night Test) across all the three study groups did not show statistically significant differences $(F(2,39)=0.917, p=0.05)$. However, there was statis-

Table 2: Mean scores (and standard deviations) of groups on the executive tests.

\begin{tabular}{|c|c|c|c|}
\hline Tasks & Monolingual Children & Children with SLI & Bilingual Children \\
\hline Day and Night Task & $13.92( \pm 0.37)$ & $13.35( \pm 0.46)$ & $14.07( \pm 0.33)$ \\
\hline Luria's Hand Task & $12.78( \pm 0.26)$ & $10.92( \pm 0.28)$ & $12.85( \pm 25)$ \\
\hline Forward Digit Span Task & $7.00( \pm 0.46)$ & $3.78( \pm 0.33)$ & $5.71( \pm 50)$ \\
\hline Backward Digit Span Task & $2.28( \pm 0.42)$ & $2.00( \pm 0.39)$ & $4.85( \pm 44)$ \\
\hline Phonemic Fluency/k/ & $5.21( \pm 0.45)$ & $2.28( \pm 0.42)$ & $4.85( \pm 45)$ \\
\hline Phonemic Fluency/b/ & $3.14( \pm 0.46)$ & $1.28( \pm 0.26)$ & $2.85( \pm 45)$ \\
\hline Semantic Fluency (Animals) & $9.57( \pm 1.17)$ & $5.35( \pm 1.10)$ & $7.35( \pm 0.78)$ \\
\hline Semantic Fluency (Girls/Boys names) & $8.42( \pm 0.69)$ & $3.35( \pm 0.65)$ & $5.57( \pm 0.85)$ \\
\hline
\end{tabular}


Table 3: ANOVA results of the groups on executive tasks.

\begin{tabular}{|c|c|c|c|c|c|c|c|}
\hline Test & Source of Variance & Sum of Squares & df & $\begin{array}{l}\text { Mean } \\
\text { Square }\end{array}$ & $\mathbf{F}$ & $\mathbf{p}$ & $\begin{array}{l}\text { Multiple } \\
\text { Comparisons }\end{array}$ \\
\hline \multirow[t]{3}{*}{ Day and Night } & Between Groups & 4 & 2 & 2 & & \multirow[t]{3}{*}{0.13} & \multirow[t]{3}{*}{$1 \approx 2 \approx 3$} \\
\hline & Within Groups & 85.07 & 39 & 2.18 & 0.917 & & \\
\hline & Total & 89.07 & 41 & & & & \\
\hline \multirow[t]{3}{*}{ Luria's Hand Game } & Between Groups & 33.47 & 2 & 16.73 & & \multirow[t]{3}{*}{0.5} & \multirow[t]{3}{*}{$1<2 \approx 3$} \\
\hline & Within Groups & 39 & 39 & 1 & 16.738 & & \\
\hline & Total & 72.47 & 41 & & & & \\
\hline \multirow[t]{3}{*}{ Digitspan Forward } & Between Groups & 73.28 & 2 & 36.64 & & \multirow[t]{3}{*}{0} & \multirow[t]{3}{*}{$1<2 \approx 3$} \\
\hline & Within Groups & 107.21 & 39 & 2.74 & 13.329 & & \\
\hline & Total & 180.5 & 41 & & & & \\
\hline \multirow[t]{3}{*}{ Digitspan Backwards } & Between Groups & 69.33 & 2 & 34.66 & & \multirow[t]{3}{*}{0} & \multirow[t]{3}{*}{$3>1 \approx 2$} \\
\hline & Within Groups & 96.57 & 39 & 2.47 & 14 & & \\
\hline & Total & 165.9 & 41 & & & & \\
\hline \multirow[t]{3}{*}{ Phonemic Fluency (/k/) } & Between Groups & 71.47 & 2 & 35.73 & \multirow[t]{3}{*}{12.795} & \multirow[t]{3}{*}{0.5} & \multirow[t]{3}{*}{$1<2 \approx 3$} \\
\hline & Within Groups & 108.92 & 39 & 2.79 & & & \\
\hline & Total & 180.4 & 41 & & & & \\
\hline \multirow[t]{3}{*}{ Phonemic Fluency (/b/) } & Between Groups & 28 & 2 & 14 & & \multirow[t]{3}{*}{0} & \multirow[t]{3}{*}{$1<2 \approx 3$} \\
\hline & Within Groups & 90.28 & 39 & 2.31 & 6.047 & & \\
\hline & Total & 118.28 & 41 & & & & \\
\hline \multirow{4}{*}{$\begin{array}{l}\text { Semantic Fluency } \\
\text { (Animals) }\end{array}$} & \multirow[t]{2}{*}{ Between Groups } & \multirow[t]{2}{*}{124.42} & \multirow[t]{2}{*}{2} & \multirow[t]{2}{*}{62.21} & & & \\
\hline & & & & & & 0 & $2>3 \approx 2$ \\
\hline & Within Groups & 585.85 & 39 & 15.02 & 4.142 & & \\
\hline & Total & 710.28 & 41 & & & & \\
\hline \multirow{3}{*}{$\begin{array}{l}\text { Semantic Fluency (The } \\
\text { Names of Girls/Boys) }\end{array}$} & Between Groups & 181 & 2 & 90.5 & & & \\
\hline & Within Groups & 298.07 & 39 & 7.64 & 11.841 & 0 & $2>1 \approx 3$ \\
\hline & Total & 479.07 & 41 & & & & \\
\hline
\end{tabular}

1 = Children with SLI; 2 = Monolingual Turkish speaking children with typical development; $3=$ Turkish-German bilingual children with typical development.

tically significant differences between groups in terms of nonverbal conflict inhibition task determined by Fist and Finger Test $(F(2,39)=16.738, p=0.001)$. A Tukey post-hoc test revealed that the performance of children with S/LI (10.9 \pm 0.28$)$ was significantly lower than children with TD $(12.78 \pm 0.26, p=0.001)$ as well as bilingual children (12.85 $\pm 0.50, p=0.25$ this is not significant). The comparison of children with TD and bilingual groups showed no significant differences in this respect $(p=$ 0.981).

\section{Short term memory and working memory in mono- lingual, bilingual and children with specific language impairment}

There was a statistically significant difference between groups in terms of short term memory determined by one-way ANOVA $(F(2,39)=13.32, p=0.001)$. The Digitspan Forward performance of the group with $\mathrm{S} / \mathrm{LI}(3.7 \pm 0.33)$ was statistically significantly lower than the TD group $(7.00 \pm 0.46, p=0.001)$ and bilingual group $(5.7 \pm 0.50, p=0.010)$. There was no statistically significant difference between the TD and bilingual children $(p=0.113)$.

There were also statistically significant differences between groups in terms of working memory as determined by one-way ANOVA $(F(2,39)=14.00, p=0.001)$. The Digitspan Backwards performance of the bilingual group $(4.8 \pm 0.44$,$) was statistically significantly high-$ er than the S/LI group $(2.00 \pm 0.39 p=0.001)$ and TD group $(2.2 \pm 0.42, p=0.001)$. There was no statistically significant difference between the TD and $S / L I$ group ( $p$ $=0.881$ ).

\section{Semantic and phonemic fluency in monolingual, bi- lingual and children with specific language impair- ment}

The difference between groups was significant with regard to Phonemic Fluency Task (i.e. $/ \mathrm{k} /)(\mathrm{F}(2,39)=$ 12.79, $p=0.001$ ) as determined by one-way ANOVA. Tukey post-hoc test showed that the performance of S/ $\mathrm{LI}$ group was $(2.2 \pm 0.42)$ significantly lower than the TD group $(5.2 \pm 0.45, p=0.001)$ and the bilingual group ( 4.8 $\pm 0.45, p=0.001$ ). There was no statistically significant difference between the TD and the bilingual group ( $p=$ 0.839).

There was a statistically significant difference between groups as determined by one-way ANOVA in terms of Phonemic Fluency (i.e. /b/) $(F(2,39)=6.047, p$ $=0.005)$. The performance of $\mathrm{S} / \mathrm{LI}$ group was $(1.2 \pm 0.26)$ significantly lower than the TD group $(3.1 \pm 0.46, p=$ $0.007)$ and bilingual group $(2.8 \pm 0.45, p=0.025)$. There was no statistically significant difference between the TD and bilingual group ( $p=0.839)$.

The difference between groups determined by one- 
way ANOVA in terms of Semantic Fluency (i.e. animals) $(F(2,39)=4.14, p=0.023)$ was significant. The performance of TD group was $(9.5 \pm 1.1)$ significantly higher than the children with $S / L I(5.35 \pm 1.1, p=0.017)$. There were no statistically significant differences between the $S / L I$ and bilingual groups $(p=0.369)$ or bilingual and the TD group $(p=0.297)$.

There was also statistically significant difference between groups as determined by one-way ANOVA test in terms of Semantic Fluency (i.e. girls/boys names) ( $F(2$, $39)=11.84, p=0.001$ ). The performance of TD group $(8.4 \pm 0.69, p=0.001)$ was significantly higher than the S/LI group ( $3.3 \pm 0.65)$ and bilingual group $(5.57 \pm 0.85, p$ $=0.025)$. There was no statistically significant difference between the $S / L I$ and the bilingual group $(p=0.099)$.

\section{Discussion}

The aim of the present study was to compare three groups of children, namely children with S/LI between 5-6 year-olds, their age and gender matched monolingual Turkish speaking children with typical development and Turkish-German bilingual children on executive tasks assessing conflict inhibition, short term memory, working memory and fluency. On all executive functions tasks used in this study, children with S/LI scored at a lower level compared to other two groups.

Specifically, based on Digitspan Forward Test measuring short term memory, children with $\mathrm{S} / \mathrm{LI}$ obtained significantly lower scores than children with typical development and Turkish-German speaking bilingual children. Monolingual children with typical development scored higher than bilinguals although the difference was not statistically significant. These results are expected and in parallel with a vast amount of previous research reporting short term memory deficits in children with $S / L I ~[25,30]$. Bilingual children outperformed children with $\mathrm{S} / \mathrm{LI}$ on Digitspan Backward task which requires processing besides storage. Although bilingual children' scores on this task were higher than children with typical development, group differences just failed to reach the criterion for statistical significance. These results are also consistent with recent increasing studies of bilingual advantage on working memory tasks [47-50]. Bilingual superiority in working memory tasks are thought to be arising from the continuous selection and processing of lexical information in two languages. Recent models of lexical access in bilinguals reveal that lexical items in both languages remain active in bilinguals independent of the language required for a task [51-53]. The pattern of the performance of bilingual children on inhibition and working memory tasks finds support for the Inhibitory Control Model and Adaptive Control Hypothesis $[54,55]$. These models assert that bilinguals use these mechanisms more proficiently than monolinguals due to continuous management of the two languages.

However, it is a quite surprising result that there was not any significant difference between groups in terms of Day \& Night Task assessing verbal conflict inhibition although the scores of bilinguals were higher than the other groups. This is probably due to the fact that the task was easy for this age group since the scores of the three groups was so high. We should also remember [41] reports about the performance on the day-night task improved in children between the ages of 3.5 and 5.0 years. Accordingly, it is claimed that children older than age 5 years may show performance near the maximum [56]. Further research is needed to establish validity and reliability of this task for 5 and 6-year-old in Turkey. On the other hand, significant group differences were found for the Fist \& Finger task measuring nonverbal conflict inhibition. Children with S/LI scored lower when compared with the other two groups. The results of this study tend to be in line with the results of previous studies carried with children with $\mathrm{S} / \mathrm{LI}$ in confirming the evidence for nonverbal inhibition dysfunction in this group [5,57-60]. Our results further support the hypothesis that individuals with $\mathrm{S} / \mathrm{LI}$ have broad executive difficulties that are not restricted to the verbal tasks only [21].

Children with typical development produced significantly higher responses on semantic fluency task than the other groups. With regard to performance on phonemic fluency task, children with S/LI performed significantly lower than the other two groups. These results are also consistent with previous studies that found problems in these domains in children with $\mathrm{S} / \mathrm{LI}$ both in terms of efficiency [61] and accuracy [62]. These findings also support the hypotheses that fluency also depending on some elements of executive functions, namely inhibition and working memory since group with $\mathrm{S} / \mathrm{LI}$ also have lower performance on these tasks too [63]. However bilingual group scored lower than children with typical development on fluency tasks although their inhibition and working memory scores were the highest. This is probably due to the fact that bilinguals in our sample were all sequential learners and were living in their L2 country. Although their L1 (Turkish) language test scores were within normal limits, their experience with Turkish in their daily lives was limited. Another possible reason of these findings is continuous competition between two languages during retrieval. Bilingual children are found to be slower on picture naming tasks [64] and showing poorer performance on verbal fluency tasks $[65,66]$ although they have similar conceptual vocabulary with their monolingual peers $[67,68]$. So, future researches should also include tasks or batteries encompassing novel word learning tasks with measuring reaction times. This form of study would allow the lexical abilities of bilinguals to be thoroughly examined.

There are a number of limitations associated with the current study that must be carefully considered when interpreting its results. The main limitation of this study is the small sample size. More research is needed 
that involve a larger sample with a wider age range as well as longitudinal analyses. The second limitation is the lack of of the bilingual children with S/LI which is a very hard to reach. With a large enough sample size, this form of study would allow seeing the possible cognitive advantages/disadvantages of bilingualism on language development.

In summary, this study adds to the evidence that children with S/LI demonstrate executive function deficits both in verbal and nonverbal domains and there is a bilingual advantage in working memory and inhibition performance.

\section{Acknowledgment}

We acknowledge that "COST Action IS0804 Language Impairment in a Multilingual Society: Linguistic Patterns and the Road to Assessment" and "WG4: The role of Executive Functions in Multilingualism", where a pilot of this study was presented, gave us an opportunity to share the tests and the tasks used in this study. No grant/funding was received for this research.

\section{Conflict of Interest}

The authors declare that they have no conflict of interest.

\section{References}

1. Fresneda MD, Mendoza E (2005) Trastorno específi co de lenguaje: Concepto, clasifi caciones y criterios de identifi cación. Revista de Neurología 41: 51-56.

2. Arboleda-Ramírez A, Lopera-Vásquez JP, Hincapié- Henao L, Giraldo-Prieto M, Pineda DA, et al. (2007) Trastorno específico del desarrollo del lenguaje: Problema selectivo o generalizado de la cognición. Revista de Neurología 44: 596-600.

3. Coelho S, Albuquerque CP, Simões MR (2013) Specific language impairment: A neuropsychological characterization. Paidéia (Ribeirão Preto) 23: 31-41.

4. Dawson P, Guare R (2010) Executive skills in children and adolescents: A practical guide to assessment and intervention. ( $2^{\text {nd }}$ edn), NY: Guilford, New York.

5. Im-Bolter N, Johnson J, Pascual-Leone J (2006) Processing limitations in children with specific language impairment: The role of executive function. Child Dev 77: 1822-1841.

6. Weyandt LL, Willis WG (1994) Executive functions in school-aged children: Potential efficacy of tasks in discriminating clinical groups. Developmental Neuropsychology 10 : 27-38.

7. Wolfe CD, Bell MA (2004) Working memory and inhibitory control in early childhood: Contributions from electrophysiology, temperament and language. Dev Psychobiol 44: 6883.

8. Durston S, Thomas KM, Yang Y, Ulu AM, Zimmerman RD, et al. (2002) A neural basis for the development of inhibitory control. Developmental Science 4: 9-16.

9. Stievano P, Valeri G (2013) Executive functions in early childhood: interrelations and structural develoment of inhibition, setshifting and working memory. Neuropsychological Trend 13: 27-45.
10. Turner M (1997) Towards and executive dysfunction account of repetitive behavior in autism. In: J Russel, Autism as an executive disorder. Oxford University, New York, 57100.

11. Weckerly J, Wulfeck B, Reilly J (2001) Verbal fluency deficits in children with specific language impairment: Slow rapid naming or slow to name? Child Neuropsychol 7: 142-152.

12. Katz W, Curtiss S, Tallal P (1992) Rapid automatized naming and gesture by normal and language-impaired children. Brain Lang 43: 623-641.

13. Korhonen TT (1991) An empirical subgrouping of Finnish learning disabled children. J Clin Exp Neuropsychol 13: 259-277.

14. Levin BE (1990) Organizational deficits in dyslexia: possible frontal lobe dysfunction. Developmental Neuropsychology 6: 95-110.

15. Luteijn F, Barelds D (2004) GIT-2 Handleiding. Amsterdam: Harcourt Test Publishers.

16. Fisk JE, Sharp CA (2004) Age-related impairment in executive functioning: updating, inhibition, shifting, and access. J Clin Exp Neuropsychol 26: 874-890.

17. Henry LA, Messer DJ, Nash G (2015) Executive functioning and verbal fluency in children with language difficulties. Learning and Instruction 39: 137-147.

18. Dollaghan C (1998) Spoken word recognition in children with and without specific language impairment. Applied Psycholinguistics 19: 193-207.

19. Ellis Weismer S, Evans J, Hesketh L (1999) An examination of verbal working memory capacity in children with specific language impairment. J Speech Lang Hear Res 42: 1249-1260.

20. Montgomery JW (1995) Sentence comprehension in children with specific language impairment: The role of phonological working memory. J Speech Lang Hear Res 24: 154-161.

21. Henry LA, Messer DJ, Nash G (2012) Executive functioning in children with specific language impairment. J Child Psychol Psychiatry 53: 37-45.

22. Marton K, Schwartz RG (2003) Working Memory Capacity and Language Processes in Children with Specific Language Impairment. J Speech Lang Hear Res 46: 11381153.

23. Kyllonen P, Christal R (1990) Reasoning ability is (little more than) working memory capacity? Intelligence 14: 389433.

24. Hale JB, Hoeppner JB, Fiorello CA (2002) Analyzing digit span components for assessment of attention processes. Journal of Psychoeducational Assessment 20: 128-143.

25. Archibald LM, Gathercole SE (2006) Short-term memory and working memory in children with specific language impairments. Int J Lang Commun Disord 41: 675-693.

26. Baddeley A (2003) Working memory and language: An overview. J Commun Disord 36: 189-208.

27. Helland T, Asbjornsen A (2004) Digit span in dyslexia: Variations according to language comprehension and mathematics skills. J Clin Exp Neuropsychol 26: 31-42.

28. Montgomery J (2003) Working memory and comprehension in children with specific language impairment: What we know so far. J Commun Disord 36: 221-231.

29. Riccio C, Cash D, Cohen M (2007) Learning and memory 
performance of children with specific language impairment (SLI). Appl Neuropsychol 14: 255-261.

30. Bavin EL, Wilson PH, Maruff P, Sleeman F (2005) Spatio-visual memory of children with specific language impairment: Evidence for generalized processing problems. Int $J$ Lang Commun Disord 40: 319-332.

31. Crago M, Paradis J (2003) Two of a kind? Commonalities and variation in languages and language learners. In: $Y$ Levy, J Schaeffer, Language competence across populations: Towards a definition of a spesific language impairment. Mahwah, NJ: Lawrence Erlbaum Associates, 97-110.

32. Kohnert K, Windsor J, Ebert KD (2009) Primary or 'specific' language impairment and children learning a second language. Brain Lang 109: 101-111.

33. Thordardottir E, Ellis Weismer S (2001) High-frequency verbs and verb diversity in the spontaneous speech of school-age children with specific language impairment. Int J Lang Commun Disord 36: 221-244.

34. Paradis J (2010) The interface between bilingual development and specific language impairment. Applied Psycholinguistics 31: 3-28.

35. Bialystok E (2010) Global-local and trail-making tasks by monolingual and bilingual children: Beyond inhibition. Developmental Psychology 46: 93-105.

36. Bialystok E, Craik FI, Klein R, Viswanathan M (2004) Bilingualism, aging, and cognitive control: Evidence from the Simon task. Psychol Aging 19: 290-303.

37. Costa A, Hernández M, Costa-Faidella J, Sebastián-Gallés $\mathrm{N}$ (2009) On the bilingual advantage in conflict processing: Now you see it, now you don't. Cognition 113: 135-149.

38. Hilchey MD, Klein RM (2011) Are there bilingual advantages on nonlinguistic interference tasks? Implications for the plasticity of executive control processes. Psychon Bull Rev 18: 625-658.

39. Poarch G, van Hell J (2012) Executive functions and inhibitory control in multilingual children: Evidence from secondlanguage learners, bilinguals, and trilinguals. J Exp Child Psychol 113: 535-551.

40. Topbaş S, Guven S (2011) Turkçe Erken Dil Gelişim Testi-TEDIL Ankara: Detay Yayıncılık, Ankara.

41. Gerstadt C, Hong Y, Diamond A (1994) The relationship between cognition and action: Performance of 31/2-7-yearold children on a Stroop-like day-night test. Cognition 53 129-153.

42. Hughes C (1996) Control of action and thought: Normal development and dysfunction in autism: A research note. Journal of Child Psychology and Psychiatry 37: 229-236.

43. Wechsler D (1997) Administration and scoring manual for the Wechsler Memory Scale-Third Edition. Psychological Corp, San Antonio, TX.

44. Wechsler D (1997) Technical manual for the Wechsler Adult Intelligence Scale-Third Edition and the Wechsler Memory Scale-Third Edition. Psychological Corp, San Antonio, TX.

45. Newcombe F (1969) Missle Wounds of the Brain. A Study of Psychological Deficits, Oxford University Press, London.

46. Benton AL (1968) Differential behavioural effects in frontal lobe disease. Neuropsychologia 6: 53-60.

47. Blom E, Küntay AC, Messer M, Verhagen J, Leseman P (2014) The benefits of being bilingual: working memory in bilingual Turkish-Dutch children. J Exp Child Psychol 128 : 105-119.
48. Blom E, Boerma T, Bosma E, Cornips L, Everaert E (2017) Cognitive advantages of bilingual children in different sociolinguistic contexts. Front Psychol 8: 552.

49. Barac R, Bialystok E (2011) Cognitive development of bilingual children. Language Teaching 44: 36-54.

50. Morales J, Calvo A, Bialystok E (2013) Working memory development in monolingual and bilingual children. J Exp Child Psychol 114: 187-202.

51. Dijkstra T, Van Heuven WJB (2002) The architecture of the bilingual word recognition system: From identification to decision. Bilingualism: Language and Cognition 5: 175-197.

52. De Groot AMB, Delmaar P, Lupker SJ (2000) The processing of interlexical homographs in translation recognition and lexical decision: Support for nonselective access to bilingual memory. Q J Exp Psychol A 53: 397-428.

53. Dijkstra A, Van Jaarsveld H, Ten Brinke S (1998) Interlingual homograph recognition: Effects of task demands and language intermixing. Bilingualism: Language and Cognition 1: 51-66.

54. Green DW (1998) Mental control of the bilingual lexico-semantic system. Bilingualism: Language and Cognition 1: 67-81.

55. Green DW, Abutalebi J (2013) Language control in bilinguals: the adaptive control hypothesis. J Cogn Psychol 25: 515-530.

56. Ikeda Y, Okuzumi H, Kokubun M, Haishi K (2011) Age-related trends of interference control in school-age children and young adults in the Stroop color-word test. Psychol Rep 108: 577-584.

57. Bishop DVM, Norbury CF (2005) Executive functions in children with communication impairments, in relation to autistic symptomatology. Autism 9: 29-43.

58. Finneran D, Francis A, Leonard L (2009) Sustained attention in children with specific language impairment. J Speech Lang Hear Res 52: 915-929.

59. Marton K, Kelmenson L, Pinkhasova M (2007) Inhibition control and working memory capacity in children with SLI. Psikhologyah 50: 110-121.

60. Spaulding T, Plante E, Vance R (2008) Sustained selective attention skills of preschool children with specific language impairment: Evidence for separate attentional capacities. $J$ Speech Lang Hear Res 51: 16-34.

61. Kail R, Leonard LB (1986) Word-finding abilities in language-impaired children (ASHA Monographs 25). Rockville, MD: American Speech-Language-Hearing Association.

62. Rubin H, Liberman I (1983) Exploring the oral and written language errors made by language disabled children. Annals of Dyslexia 33: 110-120.

63. Shao Z, Janse E, Visser K, Meyer AS (2014) What do verbal fluency tasks measure? Predictors of verbal fluency performance in older adults. Front Psychol 5: 772.

64. Windsor J, Kohnert K (2004) The search for common ground: part I. Lexical performance by linguistically diverse learners. J Speech Lang Hear Res 47: 877-890.

65. Sandoval TC, Gollan TH, Ferreira VS, Salmon DP (2010) What causes the bilingual disadvantage in verbal fluency? The dual-task analogy. Bilingual Lang Cogn 13: 231-252.

66. Kormi-Nouri R, Moradi AR, Moradi S, Akbari-Zardkhaneh S, Zahedian $\mathrm{H}$ (2012) The effect of bilingualism on letter and category fluency tasks in primary school children: Advan- 
tage or disadvantage? Bilingual Lang Cogn 15: 351-364.

67. Pearson BZ, Fernandez SC, Oller DK (1993) Lexical development in bilingual infants and toddlers: Comparison to monolingual norms. Language Learning 43: 93-120.
68. Bedore LM, Pena ED, Garcia M, Cortez C (2005) Conceptual Versus Monolingual Scoring: When Does It Make a Difference? Lang Speech Hear Serv Sch 36: 188-200. 